\section{Consider celiac disease}

Re: "Idiopathic small-bowel intussusception in an adult." An important but under-recognized etiology of adult small bowel intussusception without a "lead point" is celiac disease. In rare cases, intussusception may be the initial presentation of adult celiac disease. If not done already, the patient in the present case, even if asymptomatic, should be investigated for this possibility.

\section{Andrew Mitchell MD}

Hôpital Maisonneuve-Rosemont, Montréal, Que.

\section{REFERENCE}

1. Renzulli P, Candinas D. Idiopathic small-bowel intussusception in an adult. CMAJ 2010;182:E148.

For the full letter, go to: www.cmaj.ca/cgi/eletters /182/3/E148\#320869

DOI:10.1503/cmaj.110-2060

\section{Pets in airplane cabins: Pro}

As an academic physician and a pilot, I was outraged by this editorial. ${ }^{1}$ The unsupported statement "Pets can be accommodated comfortably and safely in airplane cargo holds, which is where they belong" got my dander up. A cursory Internet search brought up documented accounts of hundreds of companion animals that have perished in cargo holds. Cargo holds are usually not heated, air conditioned or pressurized and often are unventilated in order to reduce fire hazard. People do need to sometimes travel with pets and it is

\section{Letters to the editor}

In submitting a letter, you automatically consent to have it appear online and/or in print. All letters accepted for print will be edited by $C M A J$ for space and style. Most references and multiple authors' names and full affiliations will appear online only. (The full version of any letter accepted for print will be posted at cmaj.ca.) wrong to send the pets to the cargo hold. Most (not all) pet allergies are due to direct contact, not proximity to pets, which can be minimized by keeping the pets in travel cages. Are you next going to suggest banning people who might have pet hair or dander on their clothes from flights because of the theoretical possibility that they may also cause allergies in the susceptible? The evidence is about the same.

\section{W. David Colby MSc MD}

Associate professor, microbiology \& immunology, Schulich School of Medicine and Dentistry, University of Western Ontario, London, Ont.

\section{REFERENCE}

1. Stanbrook MB, Kovesi T, Hébert PC. Pets in airplane cabins: an unnecessary allergic hazard. CMAJ 2010;182:421.

For the full letter, go to: www.cmaj.ca/cgi/eletters /182/5/421\#334758

DOI:10.1503/cmaj.110-2067

\section{Pets in airplane cabins: Con}

The Canadian Society of Allergy and Clinical Immunology welcomes your recent editorial regarding pets in airplane cabins. ${ }^{1}$ It was through the society that Air Canada made its decision in 2006 to ban the carriage of pets on board, because of the dangers to passengers with serious animal dander allergies. When Air Canada reversed this policy in July 2009, we contacted them immediately to express our concerns. We have also discussed these issues with WestJet. As the national society representing allergists and clinical immunologists throughout Canada, and with the welfare of our patients firmly in mind, we support the effort to allow pet-allergic individuals to travel by air in safety and comfort.

\section{R.J. Warrington BSc MB PhD}

President of the Canadian Society of Allergy \& Clinical Immunology, Winnipeg, Man.

\section{REFERENCE}

1. Stanbrook MB, Kovesi T, Hébert PC. Pets in air- plane cabins: an unnecessary allergic hazard. CMAJ 2010;182:421.

For the full letter, go to: www.cmaj.ca/cgi/eletters /182/5/421\#294587

DOI:10.1503/cmaj.110-2066

\section{Predictive genotype}

The article by Fernando and Broadfoot ${ }^{1}$ summarizes the important issues of drug-induced severe skin reactions. It is very important to note that genotypebased identification of those Han Chinese patients who may develop severe skin reactions to carbamazepine is now possible. However, we need to clearly understand a downside of this approach. Namely, a positive predictive value of the HLA- B*1502 genotyping is only $7.7 \%$, as the authors suggested, or may be even less. The authors' statement that "in 3\% of patients who are test-positive, the disease may never develop with exposure to carbamazepine" could be interpreted in different ways. Because the $3 \%$ is a false positive rate of the genotyping test in Han Chinese, it is better to state as follows: "If we test 1000 Han Chinese patients who will never develop the severe skin reactions to carbamazepine, 30 of them $(3 \%)$ will be positive on the HLA- B*1502 genotyping."

\section{Shinya Ito MD}

Division of Clinical Pharmacology and Toxicology, Hospital for Sick Children, University of Toronto, Toronto, Ont.

Bruce C. Carleton PharmD

Pharmaceutical Outcomes Programme, BC Children's Hospital, University of British

Columbia, Vancouver, BC

\section{REFERENCE}

1. Fernando SL, Broadfoot AJ. Prevention of severe cutaneous adverse drug reactions; the emerging value of pharmacogenetic screening. CMAJ 2010; 182:476-80.

For the full letter, go to: www.cmaj.ca/cgi/eletters /182/5/476\#322816

DOI:10.1503/cmaj.110-2061

\section{Driving for seniors}

The editorial on driving and seniors ${ }^{1}$ addresses some of the problems that are 
often overlooked when discussing driving assessment for senior citizens. People are often even more dependent on being able to drive than when they were younger and more able to walk and take public transportation.

One of the most difficult problems is deciding when a patient with cognitive impairment is no longer safe to drive. Routine neuropsychology tests are probably not going to detect borderline cases, and everyone who has memory problems is not necessarily a safety risk. In my mind, the gold standard is a lengthy on-road driving test. There was a time when governments covered this but it is now downloaded to private companies, who charge between $\$ 500$ and $\$ 800$. One idea that I have never heard discussed is having the insurance companies pay for testing. When you have a major accident or loss of life they pay thousands if not millions. Why do they not insist that they first assess your driving abilities and make a risk assessment before they insure you?

\section{Robert F. Nelson MD}

Neurologist, Élizabeth-Bruyére Hospital, Ottawa, Ont.

\section{REFERENCE}

1. MacDonald N, Hébert PC. Driving retirement program for seniors: long overdue. CMAJ 2010 182:645.

For the full letter, go to: www.cmaj.ca/cgi/eletters /cmaj.100273v1\#321774

DOI:10.1503/cmaj.110-2063

\section{The philosophy of medicine}

Professor Croskerry's article ${ }^{1}$ argues for training of medical students in critical thinking to reduce medical error. Although this is a reasonable argument, there is scant evidence to support it as not much relevant research has been published to date. A notable exception is the training of medical students in philosophy of medicine, which focuses to a large extent on general methodology of medicine and has demonstrated success and satisfaction. ${ }^{2}$ It may be beneficial to develop, implement and study various ways of training medical students and practitioners in the philosophy of medicine, and to study whether such training enhances their critical thinking and reduces medical error.

\section{Abraham Rudnick MD PhD}

Associate professor, Departments of Psychiatry and Philosophy, University of Western Ontario, London, Ont.

\section{REFERENCES}

1. Croskerry P. To err is human — and let's not forget it. CMAJ 2010;182:524.

2. Rudnick A. An introductory course in philosophy of medicine. Medical Humanities 2004;30:54-6.

For the full letter, go to: www.cmaj.ca/cgi/eletters /182/5/524\#313438

DOI:10.1503/cmaj.110-2057

\section{Register systematic reviews}

Straus and Moher call for "a registry of protocols for systematic reviews and of completed reviews."' We agree that such a registry would, among other things, help reduce publication bias, promote transparency and enhance collaboration. Following the lead of early registers of published trials and the Cochrane Central Register of Controlled Clinical Trials, we started building a register of reports of vision science systematic reviews in 2006. ${ }^{2}$ This has proven to be an invaluable central repository. For example, we have used it to develop methods for which eyes and vision systematic reviews should be done first, to conduct methodological research and to initiate collaborations with guideline developers and professional societies.

We believe the database will have a pivotal role in facilitating the use of systematic review evidence in health care decision-making.

\section{Tianjing Li MD and colleagues}

Center for Clinical Trials, Johns Hopkins

Bloomberg School of Public Health,

Baltimore, Md.

\section{REFERENCES}

1. Straus S, Moher D. Registering systematic reviews. CMAJ 2010;182:13-4.

2. Li T, Scherer R, Twose C, et al. Identification and characterization of systematic reviews in eyes and vision. 15th Cochrane Colloquium; 2007 Oct 23-27; São Paulo, Brazil. Available at: www.imbi.uni- freiburg.de /OJS/cca/index.php/cca/article/view/5054 (accessed 2010 Apr 2).

For the full letter go to: www.cmaj.ca/cgi/eletters /182/1/13\#324055

DOI:110-2064
When FPG is Within Target

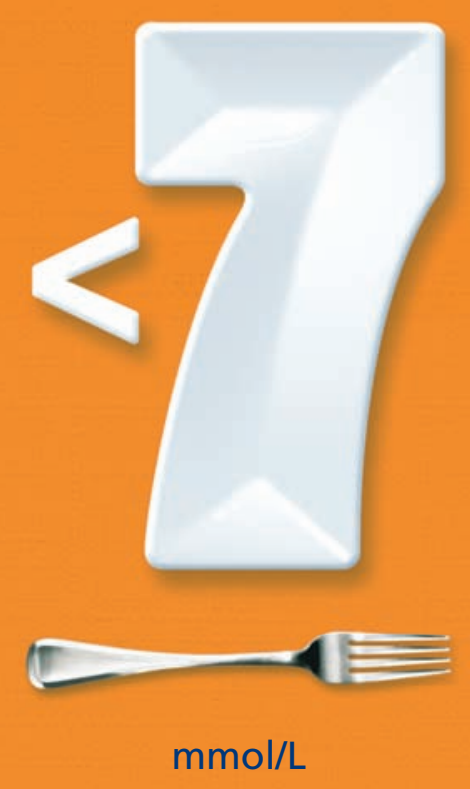

but $\mathbf{A} 1 \mathbf{C}$ is Above Target

\section{What's Your} PROTOCOL?

PG = Fasting Plasma Glucose Target glycemic ranges recommended by the Canadian Diabetes Associatio 2008 Clinical Practice Guidelines for the Prevention and Management of Diabetes in Canada. 